\title{
In-process alloying of the white layer of a workpiece machined by die-sinking EDM
}

\author{
Prof. Dr. Ir. J.-P. Kruth*, Prof. Dr. Ir. L. Froyen, Ir. L. Stevens*, Ir. P. Dejonghe*
}

(Received on April 9, 1997)

\begin{abstract}
* K.U.Leuven, Dept. of Mechanical Engineering, Div. PMA, Celestijnenlaan.300B, 3001 Heverlee, Belgium
- K.U.Leuven, Dept. of Metallurgy and Materials Engineering, De Croylaan 2, 3001 Heverlee, Belgium http://www.mech.kuleuven.ac.be/pma/pma.html
\end{abstract}

\begin{abstract}
The aim is to improve the surface quality of EDMed workpieces by in-process alloying of the white layer. Two alloying methods are investigated: using compacted powder electrodes and using powder suspended dielectrics. Both methods are able to alloy the white layer of the machined workpiece if inverse polarity is used (workpiece positive, electrode negative). When using powder electrodes, the alloying percentage is inversely proportional to the density of the electrode. Alloying percentages of more than $40 \%$ can be obtained. When using powder suspended dielectrics, the applied regimes have to be even less powerful than with the powder electrodes to enable alloying. In this case, alloying percentages of more than $10 \%$ can be achieved.

Test results show that it is possible to obtain a more corrosion resistant surface with a higher hardness and less micro cracks resulting in a longer lifetime of the workpiece.
\end{abstract}

Key words: die-sinking EDM, surface quality, alloying, injection moulds

\section{INTRODUCTION}

The heat, generated during the EDM process creates a molten and resolidified layer (the so-called "white layer") and a heat affected zone (HAZ) at the surface of the workpiece. The white layer and the HAZ have other metallurgical and mechanical characteristics than the underlying base material: in the heat affected zone, microstructural features such as grain size or even phases can change; in the white layer, even the chemical composition of the layer can be changed ${ }^{1,3,4), 11}$. When machining in an oil dielectric, carbon from the dielectric is absorbed by the white layer and small amounts of the electrode material can be found too ${ }^{3) 10 \text { ) }}$.

This paper explores the possibilities of bringing alloying elements into the white layer and thereby changing the chemical composition, in order to improve the surface quality of the workpiece.

By alloying the white layer with well-chosen materials, the surface of the workpiece can be made as desired harder, more corrosion resistant, smoother and the number of micro cracks can be reduced, which results in an improved fatigue strength.

In applications where strong and repetitive mechanical forces prevail, the white layer must be removed because of its brittleness and the presence of micro cracks that significantly reduce the fatigue resistance of the workpiece. For this kind of applications, alloying will not be used.

Improvement of the surface quality by means of alloying is especially suited for plastic injection moulds where resistance against corrosion and abrasive wear is of major importance.

Alloying with EDM has the advantage that not the whole workpiece must be made of (expensive) material with a high hardness or with excellent corrosion resistance: only the surface or parts of the surface can be treated as necessary. The requested surface quality is already obtained during the EDM process; no post-treatment like coating is needed.

\section{EXPERIMENTAL CONDITIONS}

The workpieces for the experiments are cylinders with a diameter of $22 \mathrm{~mm}$ and are machined with a die-sinking EDM machine (Charmilles Roboform 200). All tests are carried out in an oil dielectric (BP 180 with a viscosity of $1.75 \mathrm{cSt}$ at $20^{\circ} \mathrm{C}$ or BP 250 with a viscosity of $6.0 \mathrm{cSt}$ at $20^{\circ} \mathrm{C}$ ). For some of the tests, powder is brought into suspension, which will be discussed further in the text. Several regimes are 
used. To obtain a white layer, which is sufficiently thick to perform hardness measurements, stronger regimes are applied. For more realistic test pieces (alloying will only be used for finishing the workpiece) less powerful regimes are chosen.

Three different steel grades are used: Sverker 3 (X210CrW12), Impax (40CrMnMo7) and Orvar (X40CrMoV51). The chemical composition of these materials are shown in table 1 .

Table 1 Chemical composition of the different steel grades (given in weigth \%)

\begin{tabular}{|l|c|c|c|c|c:c:c:c|}
\cline { 2 - 8 } \multicolumn{1}{c|}{} & $\mathrm{C}$ & $\mathrm{Si}$ & $\mathrm{Mn}$ & $\mathrm{Cr}$ & $\mathrm{W}$ & $\mathrm{Ni}$ & $\mathrm{Mo}$ & $\mathrm{V}$ \\
\hline Sverker3 & 2.05 & 0.3 & 0.8 & 12.5 & 1.3 & - & - & - \\
\hdashline Impax & 0.37 & 0.3 & 1.4 & 2.0 & - & 1.0 & 0.2 & - \\
\hdashline Orvar & 0.39 & 1.0 & 0.4 & 5.2 & - & - & 1.4 & 0.9 \\
\hline
\end{tabular}

After machining, the surface roughness is measured with a Form Talysurf 120 from Rank Taylor Hobson. Then, a small piece is cut out to investigate the cross section with a light microscope (Leitz Metalloplan) and a scanning electron microscope (Philips SEM 515 ) with micro analysis equipment (Tracor Northern 54.02). With these tests, the degree of alloying can be investigated in function of the depth. The micro hardness is measured with a Leitz Durimet 2 with a load of $25 \mathrm{~g}$.

\section{ALLOYING WITH ELECTRODES}

When using a normal copper electrode, some electrode material (normally less than 1\%) is transferred to the workpiece, especially when working with inverse polarity (workpiece positive, electrode negative). The intention is to use this effect to insert specific materials into the workpiece ${ }^{2)}$ and to improve in this way the surface quality.

\subsection{Working conditions}

In order to make an electrode that will provide the desired alloying effect, powder is compacted in a press. Relatively high pressures are necessary to avoid the disintegration of the electrode during machining: pressures from 200 to $400 \mathrm{MPa}$ are used. For some tests, a mixture of two powders is used. In that case, it is important to mix the powders sufficiently. Failure to do this will normally result in a loosely bound electrode, which quickly falls apart during machining.
The resulting electrode, after compacting the powder, has a density of 60 to $80 \%$. The bindings between the powder particles are rather loose, which results in a high electrode wear, increasing the possibility of alloying the surface. A disadvantage of such loosely compacted electrode is that often large particles break out of the electrode, resulting in bad EDM conditions (short circuits, retraction of the electrode, obstruction of the gap). To avoid these problems, the electrode can be sintered to increase the density. For the tests, a Linn High Term 1800 furnace is used with a protective atmosphere of $90 \%$ $\mathrm{Ar}$ and $10 \% \mathrm{H}_{2}$. During the sintering process, the electrode is heated to a high temperature (but still below its melting point) to reinforce the bridge connections between the powder grains by diffusion of atoms. After sintering, a density of 80 to almost $100 \%$ is obtained, depending on electrode material and sintering temperature and time.

In the tests, the electrodes are cylindrical with a diameter of $50 \mathrm{~mm}$ and a thickness of 5 to $10 \mathrm{~mm}$. A special electrode holder is used to clamp the electrode. Care must be taken that a good electrical contact with the machine generator is obtained. A variety of powders are chosen to produce the electrodes. Materials like $\mathrm{Ni}, \mathrm{Cr}$ or $\mathrm{W}$ are used to increase the hardness. To reduce the number of micro cracks, materials like $\mathrm{Si}, \mathrm{Fe}, \mathrm{Co}$ or $\mathrm{Mn}$ can be selected, because it is known from the founding industry $^{8)}$ that these alloying elements have the capability of reducing the solidification shrinkage.

For the first tests, rather strong regimes (current $16 \mathrm{~A}$, pulse time $200 \mu \mathrm{s}$ ) are used so that a white layer with a thickness of 30 to $60 \mu \mathrm{m}$ is obtained, which facilitates the different mechanical and metallurgical tests. Later, also finer regimes (current $6 \mathrm{~A}$, pulse time $3.2 \mu \mathrm{s}$ ) are used. The tests show that machining is rather unstable, especially with electrodes which are only compacted and not sintered. One reason are the sometimes large particles $(\varnothing 0.5 \mathrm{~mm})$ that disintegrate from the electrode. To solve this problem, the electrode is constantly spinning around its axis, a good lateral flushing is applied, and powder is added to the dielectric. (This powder can be different from the electrode material.) It is known" that powder in the dielectric has a stabilising influence on the EDM process (especially when using inverse polarity) and that it has the effect of increasing the working gap, which enables a better flushing. Another reason for 
the rather unstable machining is that the electrical parameters of the EDM machining are optimised for material combinations like solid $\mathrm{Cu}$-steel or graphitesteel. The electrical and thermal behaviour of the electrode materials that are used here $(\mathrm{Ni}, \mathrm{Cr}, \mathrm{Si}, \mathrm{Co}$, $\mathrm{W}, \mathrm{Mn}, \ldots)$, however, is different.

\subsection{Overview of the results}

All the tests show that inverse polarity is necessary to obtain an alloying percentage of more than about $1 \%$. For example, a test with a solid Ni electrode using the same regime gives $1 \%$ of alloying with normal polarity and about $4 \%$ with inverse polarity. Therefore, the inverse polarity is used for all the tests.

There is also a clear influence of the porosity of the electrode: the denser the electrode, the less material is alloyed ${ }^{(5) .7)}$. The following example illustrates this. Three electrodes are used, all using a similar regime and with inverse polarity: a bulk $\mathrm{Ni}$ electrode (density $100 \%$ ), a compacted and sintered $\mathrm{Ni}$ powder electrode (compacting pressure $400 \mathrm{MPa}, \mathrm{Ni}$ powder $20 \mu \mathrm{m}$, sintered at $1200^{\circ} \mathrm{C}$ for 3 hours, density $80 \%$ ) and a $\mathrm{Ni}$ powder electrode (also compacting pressure $400 \mathrm{MPa}$, Ni powder $20 \mu \mathrm{m}$, density $65 \%$ ) which is only cold compacted and not sintered. The solid Ni electrode yields a rather constant alloying percentage in the white layer of about $3 \%$ as can be seen in figure 1 .

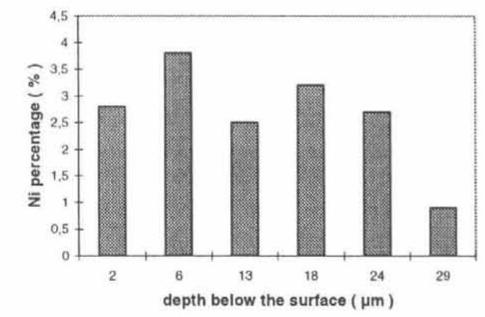

Figure $1 \mathrm{Ni}$ percentage in the white layer for the bulk Ni electrode

The white layer obtained with the compacted and sintered $\mathrm{Ni}$ powder electrode also indicates a rather constant alloying percentage, but now of $16 \%$ (figure 2).

The compacted $\mathrm{Ni}$ powder electrode gives a white layer where two zones with different $\mathrm{Ni}$ alloying percentage can be seen: in the first zone, a value of about $30 \%$ is measured; in the second zone, the alloying percentage rapidly drops to zero (figure 3 ). Note that all pictures have a different scale.
From these tests, it can be concluded that the degree of alloying is inversely proportional to the density of the electrode: the "looser" the electrode, the more material becomes available for alloying.

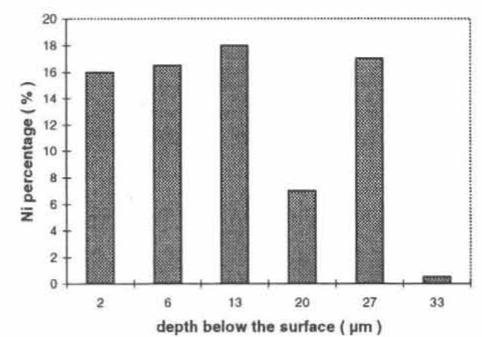

Figure $2 \mathrm{Ni}$ percentage in the white layer for the compacted and sintered Ni powder electrode

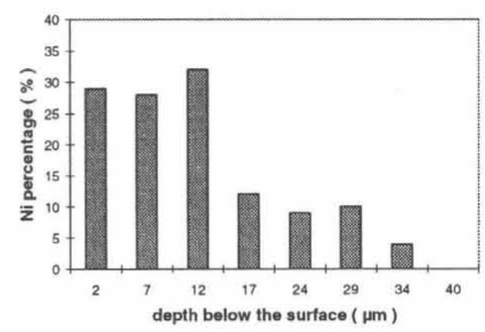

Figure $3 \mathrm{Ni}$ percentage in the white layer for the compacted $\mathrm{Ni}$ powder electrode

Different electrode materials produce different mechanical and metallurgical properties. When machining with a $\mathrm{Cr}$ electrode (powder $20 \mu \mathrm{m}$, compacting pressure $400 \mathrm{MPa}$, workpiece material Sverker 3) the surface roughness increases drastically (figure 4).

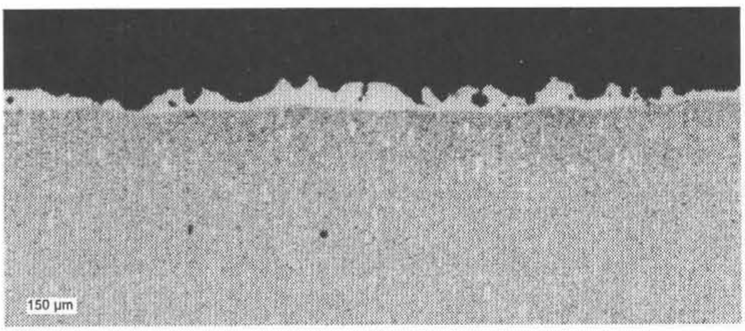

Figure 4 Transverse cut through a workpiece machined with a $\mathrm{Cr}$ electrode

On the other hand, the number of micro cracks is significantly reduced. One of the causes of these effects is probably the high melting point of $\mathrm{Cr}$ $\left(1857^{\circ} \mathrm{C}\right)$ and its rather viscous character. The mean hardness of the white layer can increase to $1500 \mu \mathrm{HV}$ (micro hardness Vickers) with maximum values up to $2200 \mu \mathrm{HV}$, which is considerably more 
than in a normal steel white layer. At the top of the white layer (some $\mu \mathrm{m}$ ) an alloying percentage of more than $90 \%$ is measured. The rest of the white layer only contains a small percentage of $\mathrm{Cr}$.

Tests with a $\mathrm{Ni}$ electrode (powder $20 \mu \mathrm{m}$, compacting pressure $400 \mathrm{MPa}$, workpiece material Sverker 3) yield a white layer which is rather even, but with a lot of micro cracks. Similarly to the $\mathrm{Cr}$ electrode, two zones with different alloying percentage can be distinguished. A mean hardness of about $1300 \mu \mathrm{HV}$ is measured.

To obtain a surface with a high hardness, but with low roughness and a limited amount of micro cracks, a combination of $\mathrm{Ni}$ and $\mathrm{Cr}$ ( $\mathrm{Cr}$ gives rough surface almost without cracks; Ni gives smoother surface but with more cracks) in the electrode seems to be a good suggestion. Therefore, a mixture of $66.7 \% \mathrm{Cr}$ and $33.3 \% \mathrm{Ni}$ is used (a stable state of $\mathrm{Cr}$ and $\mathrm{Ni}$ is a ratio of 2 to 1 ). However, this test does not yield the expected result. The roughness is reduced compared to the $\mathrm{Cr}$ electrode, but there are still a lot of micro cracks.

To diminish the amount of micro cracks, materials which tend to decrease the solidification shrinkage ( $\mathrm{Fe}, \mathrm{Co}, \mathrm{Mn}, \mathrm{Si}$ ) are selected. They are used in combination with $\mathrm{Ni}$ (high hardness, rather flat surface). Mixtures of $80 \% \mathrm{Ni}$ and $20 \%$ alloying element or $90 \% / 10 \%$ are used. The $\mathrm{NiCo}, \mathrm{NiFe}$, NiMn electrodes do not produce a real improvement in the surface quality. A lot of micro cracks are still present in the white layer. The combination of $90 \%$ $\mathrm{Ni}$ with $10 \% \mathrm{Si}$ (figure 5) on the other hand does yield promising results: almost no micro cracks are seen and there is still an increased hardness (about $880 \mu \mathrm{HV})$.

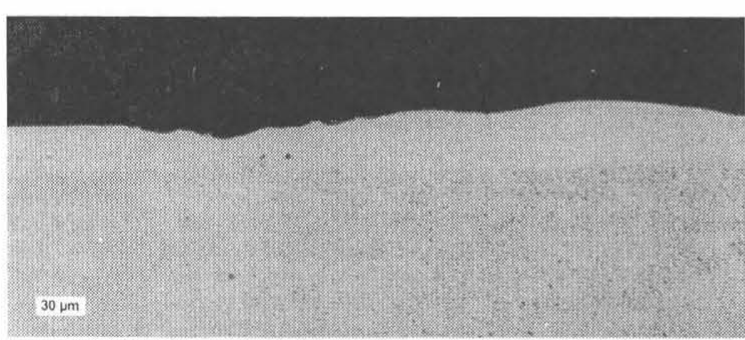

Figure 5 Transverse cut through a workpiece machined with a NiSi electrode

In the search for high hardness and good corrosion resistance, combinations of $70 \% \mathrm{Cu}$ and $30 \% \mathrm{~W}$, $\mathrm{Co}$ or $\mathrm{Mn}$ are used too. For each of these combinations, a compacted powder electrode and two sintered electrodes, with a different degree of sintering, are used. Alloying degrees vary from $1 \%$ to $16 \%$. With $\mathrm{Mn}$ and $\mathrm{W}$, micro cracks are formed when the alloying percentage exceeds $10 \%$. In the case of $\mathrm{Co}$, no micro cracks appear, even with high alloying degrees.

An overview of the results is given in table 2 .

Table 2 Overview of the powder electrodes and their effect on the surface quality

\begin{tabular}{|c|c|}
\hline Electrode material & Results \\
\hline $\mathrm{Cr}$ & $\begin{array}{l}\text { high roughness } \\
\text { few micro cracks } \\
\text { high hardness }\end{array}$ \\
\hline $\mathrm{Ni}$ & $\begin{array}{l}\text { rather low roughness } \\
\text { many micro cracks }\end{array}$ \\
\hline $\mathrm{CrNi}$ & $\begin{array}{l}\text { less micro cracks than } \mathrm{Ni} \\
\text { lower roughness than } \mathrm{Cr} \\
\text { not very satisfying }\end{array}$ \\
\hline $\begin{array}{l}\mathrm{NiCo}, \mathrm{NiMn} \\
\mathrm{NiFe}\end{array}$ & $\begin{array}{l}\text { many micro cracks } \\
\text { not better than } \mathrm{Ni}\end{array}$ \\
\hline $\mathrm{NiSi}$ & $\begin{array}{l}\text { very few micro cracks } \\
\text { low roughness } \\
\text { promising result }\end{array}$ \\
\hline $\mathrm{CuW}, \mathrm{CuMn}$ & $\begin{array}{l}\text { micro cracks with alloying } \\
\text { percentage over } 10 \% \text {, no } \\
\text { significant increase in } \\
\text { hardness with W, slight } \\
\text { increase with Mn }\end{array}$ \\
\hline $\mathrm{CuCo}$ & $\begin{array}{l}\text { no micro cracks, even with } \\
\text { higher alloying percentages, } \\
\text { no significant increase in } \\
\text { hardness with Co }\end{array}$ \\
\hline
\end{tabular}

\subsection{Difficulties}

The use of compacted powder electrodes is not without difficulties.

To start with, the material, particle size and shape, compacting pressure and (if sintering is used) sinter degree have to be chosen. Also, the electrical parameters of the EDM regimes should be optimised for the use of these electrode materials and for the alloying process.

Not all electrodes have a good electrical conductivity, not even when conductive powder is used.

Because the principle of alloying necessarily implies a rather high electrode wear, problems arise when an accurate workpiece has to be machined. Moreover, 
when larger particles wear out of the electrode, the working gap is blocked and short circuits occur. These bad working conditions result in reduced workpiece quality.

For complex workpieces, a complicated electrode shape is required which raises the problem of manufacturing such a shape. A possibility is the use of selective laser sintering (SLS). This is a rapid prototyping technique ${ }^{12)}$ which builds the workpiece layer by layer by selectively sintering metal powders with a laser.

Another, perhaps more realistic way to create complex workpieces, is to use standard shaped (e.g. cylindrical) powder electrodes and CNC EDMing of the desired contour.

\subsection{Conclusion}

The tests show that alloying with powder electrodes is feasible. When using materials like $\mathrm{Cr}, \mathrm{Ni}, \mathrm{NiSi}$ the surface of the workpiece can be made harder, more corrosion resistant ${ }^{5)}$ and with less micro cracks.

\section{ALLOYING WITH POWDERS}

The problems of making complex electrode shapes and finding the correct electrical parameters that are encountered with powder electrodes can be avoided by using powder suspended dielectric (and a normal $\mathrm{Cu}$ or graphite electrode) as a source for alloying. The idea is to bring powder into suspension in the dielectric. During the EDM process, part of this powder will be transferred towards the white layer, modifying the surface quality ${ }^{5}$.

\subsection{Working conditions}

The tests with the powder suspended dielectrics are done in a small separate dielectric container to limit the amount of powder needed and to prevent obstruction of the filter unit of the EDM machine. The powder is held in suspension with a mechanical stirrer or with a pump agitating the dielectric. Lateral flushing with the powder suspended dielectric is also available.

Different powders are selected (W, Co, Mo, Mn). When using strong regimes, no alloying effect is observed. Only with less powerful regimes (current $6 \mathrm{~A}$, pulse time $3.2 \mu \mathrm{s}$ ) alloying is possible. The particle size of the powder and the density is also of major importance. The size has to be in the micrometer range because larger particles obstruct the working gap. The density and size of the powder together with the viscosity of the dielectric determine whether the powder particles remain easily in suspension or not. Heavier particles can be held in suspension if a more viscous dielectric is used. A possibility is to bring the powder in suspension in a very viscous dielectric, which is in its turn mixed with a normal dielectric.

Because only limited power and inverse polarity regimes are used, the workpiece material removal rate and the contamination of the dielectric with chips is limited. Therefore, filtering is not really necessary. If the chips are magnetic and the powder which is brought into suspension is not magnetic, selective filtering could be used. Even in this case, however, machining is different than with the normal dielectric circuit of the EDM machine because in the small dielectric vat, the carbon percentage in the dielectric is higher (due to cracking of the dielectric).

\subsection{Overview of the results}

Although powders are normally only used to improve the stability of the EDM process or to obtain workpieces with a very low surface roughness (mirror like surfaces, roughness below $0.2 \mu \mathrm{m} \mathrm{Ra}$ ) powder suspended dielectrics can also be applied to alloy the white layer ${ }^{9), 5)}$.

Alloying only takes place with inverse polarity and when using regimes with a limited power. The regimes have to be even less powerful than when alloying with powder electrodes.

In the tests with $\mathrm{W}$ powder, alloying percentages up to $10 \%$ are measured. For alloying percentages below $5 \%$, no micro cracks are present; with higher percentages, cracks are formed.

With Mo powder, alloying percentages of $10 \%$ can also be reached, but with this powder, micro cracks are formed even with alloying percentages below $5 \%$.

\subsection{Difficulties}

As with the use of powder electrodes, a choice has to be made which material will be used, which particle size and shape and which concentration. Suitable electrical parameters have to be searched to obtain alloying.

The powder has to be held in suspension. As mentioned before, a more viscous dielectric can help, but this results in worse flushing conditions, 
especially with narrow working gaps or complex electrode shapes.

A separate dielectric circuit or an installation for selective filtering has to be developed and built in the EDM machine to prevent the powders from being filtered out of the dielectric during the roughing of the workpiece.

\subsection{Conclusions}

In addition to powder electrodes, powder suspended dielectrics can be used to alloy the surface on condition that regimes with limited power are used.

\section{GENERAL CONCLUSIONS}

Alloying with powder electrodes and alloying with powder suspended dielectrics has been investigated. Powder electrodes are made by compacting powder. If desired the electrodes can be sintered partially. Compared to powder suspended dielectrics, powder electrodes yield higher alloying percentages (more than $40 \%$ for some test pieces). The alloying percentage decreases with increasing density of the electrode.

Powder suspended dielectric shows an alloying effect if regimes with very limited power are used. Alloying percentages are lower (up to $10 \%$ ).

Both alloying methods require inverse polarity (workpiece positive, electrode negative).

\section{ACKNOWLEDGEMENTS}

This research is financed with a scholarship of the Flemish Institute for the promotion of the Scientific Technological Research in the Industry (IWT).

\section{REFERENCES}

1. Barash M., Sri-Ram M. G., Some properties of spark machined heat treated steel, The Manchester college of science and technology, 85-91

2. Dejonghe P., Lowagie P., Alloying of the white layer in EDM (in Dutch), thesis, faculty of applied science, Dpt. Mechanics, K.U.Leuven, 1995
3. Kruth J.-P., Van Humbeeck J., Stevens L., Micro structural investigation and metallographic analysis of the white layer of a surface machined by electro discharge machining, ISEM-XI, 849-862, April 1995

4. Massarelli L., Marchionni M., Morphology of spark-affected surface layers produced on pure iron and steels by electro discharge machining, Metals technology, 100-105, February 1977

5. Masui K., Demizu K., Sato Y., Sone T., Surface modification of tool steels by alloying method using EDM process, ISEM-XI, 419-426, 1995

6. Mohri N., Saito N., Tsunekawa Y., Metal surface modification by electrical discharge machining with composite electrode, Annals of the CIRP, vol. 42, 219-222, January 1993

7. Mohri N., Saito N., Suzuki M., Takawashi T., Kobayashi K., Surface modification by EDM - an innovation in EDM with semi-conductive electrodes, Proceedings of the Winter annual meeting of the ASME, vol. 34, 21-31, Chicago, USA, 1988

8. N, Metals Handbook, $9^{\text {th }}$ edition, Vol. 15, Casting, D.M. Stefanescu (editor), ASM International, Ohio, 1988

9. Narumiya H., Mohri N., Saito N., Ootake H., Tsunekawa Y., Takawashi T., Kobayashi K., EDM by powder suspended working fluid, ISEM-IX, 5-8, 1989

10. Ogata I., Mukoyama Y., Carburizing and decarburazing phenomena in EDM'd surface, Int. J. Japan Soc. Prec. Eng., vol 27 (3): 197-202, September 1993

11. Thomson P. F., Surface damage in electro discharge machining, Materials science and technology, 5: 1153-1157, November 1989

12. Van Der Schueren B., Kruth J.-P., Laser based selective metal powder sintering: a feasibility study, $26^{\text {th }}$ CIRP seminar on manufacturing systems, Proc. Laser assisted net shape engineering conference (LANE '94), Erlangen, 1994, Vol. II, 793-802 and CIRP Vol. 25/1, 1996 